\title{
Experimental Study of Slurry Flow in Mining-Induced Fractures during Longwall Overburden Grout Injection
}

\author{
Dayang Xuan, ${ }^{1}$ Jian $\mathrm{Li} \mathbb{D}^{1},{ }^{1}$ Kaidan $\mathrm{Zheng}^{1}$ and Jialin $\mathrm{Xu}{ }^{1,2}$ \\ ${ }^{1}$ School of Mines, China University of Mining and Technology, Xuzhou, Jiangsu 221116, China \\ ${ }^{2}$ State Key Laboratory of Coal Resources and Safe Mining, China University of Mining and Technology, Xuzhou, \\ Jiangsu 221116, China
}

Correspondence should be addressed to Jian Li; li_jian@cumt.edu.cn

Received 30 July 2020; Revised 22 August 2020; Accepted 26 August 2020; Published 4 September 2020

Academic Editor: Yingchun Li

Copyright (c) 2020 Dayang Xuan et al. This is an open access article distributed under the Creative Commons Attribution License, which permits unrestricted use, distribution, and reproduction in any medium, provided the original work is properly cited.

Slurry flow in mining-induced overburden fractures is an important theoretical concept for the grouting design of longwall overburden grout injection engineering. In this study, a visual experimental simulation system of longwall overburden grouting was designed to study the flow, pressure distribution, consolidation, and fill thickness of fly ash slurry in overburden bedding separation. Experiments showed that the slurry generates a radial and bidirectional flow during nonpressure grouting and presents itself as an approximately elliptical dominant flow channel under pressure injection. This channel expanded horizontally along the strike direction and gradually became tabular. The slurry pressure increased as the grouting time increased. Although the pressure curves at different locations exhibited similar trends, their values did not decrease as the distance from the borehole center decreased during observations. Bleeding and consolidation occurred in the slurry as soon as it flowed out of the borehole to the fracture, and the degree of consolidation increased as a function of the distance from the injection borehole. The bleeding water gathered continually to the boundary of the bedding separation fracture and was then seeped to and stored by the underlying strata based on the injection pressure. The final injection fill is manifested as a half pace with a large thickness at the center. This research provides a theoretical basis for the design and optimization of overburden grout injection in underground longwall mining.

\section{Introduction}

Underground longwall coal mining causes movements and breakage of strata, thus inducing vertical and horizontal fractures in the overburden [1-6]. The mining-induced fractures propagate gradually from the gob area to the ground surface and induce surface subsidence and corresponding environmental damage $[7,8]$. Meanwhile, these fractures are the flow paths of geofluids, such as methane [9], water [10,11], and slurry [12-14]; corresponding surface subsidence can be reduced by filling these fractures during mining. Grout injection into the overburden bedding fractures is one such method and is used to control mining subsidence [15-18]. Overburden grout injection involves injecting grout into mining-induced bedding fractures through surface boreholes as the longwall advances. These separations are horizontal fractures formed at the interface of strong and weak rock layers during mining. The injected fill supports the ground and reduces surface subsidence. In particular, this technology has been successfully utilized in the protection of surface infrastructures [18-22].

The dynamic flow of slurry in the overburden is the basis of injection design, such as grout take estimation, grouting pressure determination, and borehole layout. In this regard, previous research has covered the vertical injection horizon and flow radius. For example, borehole drilling [8], ground penetration radar [23], and fluorescent approach [24] have been used to locate the final injection horizon (or injection layer) in the overburden. Specifically, Xuan et al. [8] found that the injection fill is manifested as a primary injection horizon below a strong and thick rock layer (key stratum) above the injection borehole. Additionally, the flow radius of fly ash slurry was tested experimentally through two parallel disks without the simulation of mining $[25,26]$. The 


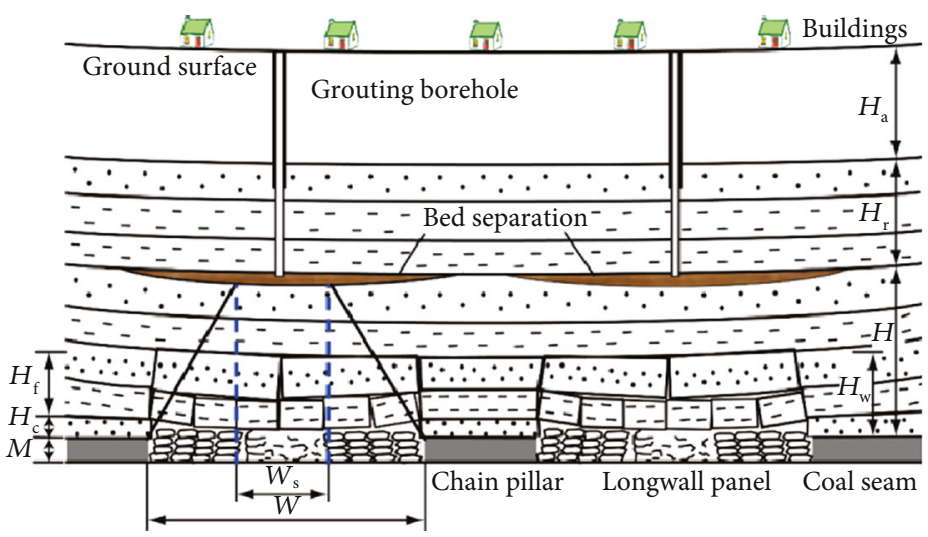

Figure 1: Principle of isolated overburden grout injection [21].

practical flow radius of a single borehole was determined for longwall overburden injection by using methods of borehole connectivity [21] and borehole imaging [23]. Studies also covered the theoretical model of the final injection fill distribution that was used to estimate the injection ratio [27].

These studies have prompted the understanding of the final fill in overburden following longwall mining with grouting. However, there is still insufficient research on the dynamic slurry flow in mining-induced overburden fractures. For the fractured rock grouting, extensive research has been conducted on grout flow with respect to experimenting and modeling [28-30]; however, the aperture of the fractures in this area differs considerably from that in longwall overburden injection engineering. The longwall-injected target is a fracture associated with underground mining; it is highly dependent on the mining height and can reach the meter level that is much larger than that in fractured rock grouting. Thus, the flow model in fractured rock is considered inapplicable to longwall overburden grout injection.

Presently, slurry flow is still unclear for the longwall injection, at least in terms of the flow channel and slurry pressure distribution in the bedding separation. Additionally, the bleeding and consolidation of the commonly used fly ash slurry that is a typical solid-liquid, two-phase flow, also need investigation in longwall overburden injection. Geophysical prospecting methods are considered insufficient to locate the slurry flow because of a large depth (usually 400-500 m below ground surface), while borehole drilling can only reveal the final fill distribution at some points instead of the entire underground bedding separation fracture.

With these issues in mind, this study utilizes an experimental methodology to (a) emulate the process of longwall overburden grout injection, (b) determine the dynamic flow, pressure distribution, and consolidation, and (c) fill the thickness of the slurry with different monitoring methods.

\section{Materials and Methods}

2.1. Theoretical Background. Isolated overburden grout injection is an improved technology for traditional longwall overburden injection $[17,18,31]$. It involves drilling surface boreholes to the selected key strata followed by the injection of slurry into the separation fracture below the strata with



FIGURE 2: Four stages of borehole injection pressure during longwall overburden grout injection [19].

high pump pressure. The high pressure generates a loadtransfer effect that supports the overlying ground and compacts underlying caved and fractured rocks, thus inducing a support system that bears the ground, and controls surface subsidence (Figure 1). This technology can increase the subsidence reduction ratio because of an improved injection ratio of up to $50-60 \%$.

Fly ash slurry, a typical solid-liquid two-phase fluid is used as the grouting material in injection engineering, and the borehole grouting pressure can reach 5-6 MPa. Following the filling in the separation zone, the slurry undergoes bleeding and consolidation under the action of grouting pressure and finally forms a compacted fill body [32]. Because a mining-induced bedding separation defines the dynamic process of the initial formation and enlargement, the injection pressure changes correspondingly, and the flow, bleeding, and consolidation of the slurry also evolve. In this regard, Teng [33] summarized the overburden grouting pressure in four stages based on actual engineering data: nonpressure, increased pressure, stabilized pressure, and overpressure (Figure 2). The grouting pressure is zero at first. This corresponds to the initial formation stage of the bedding separation. Subsequently, the grouting pressure begins to increase, thus indicating the difference between the filling speed and the formation speed of the separation fracture gradually decreases. Furthermore, the pressure reaches the weight of 


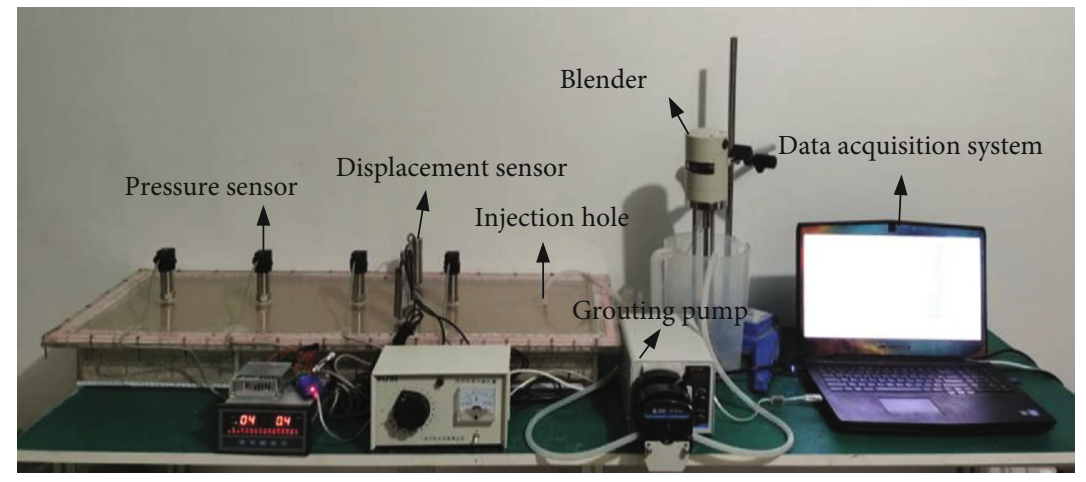

Figure 3: Experimental system.

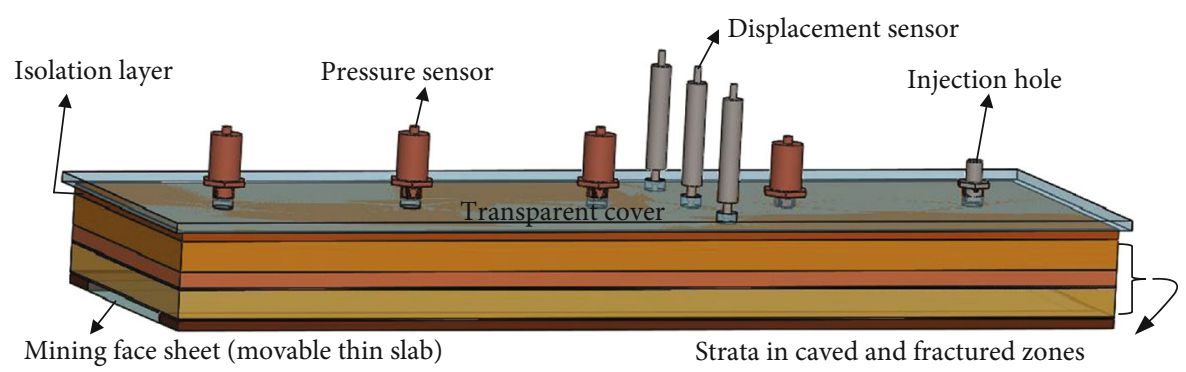

FIGURE 4: Schematic of experimental system used for the emulation.

TABLE 1: Model laying parameters.

\begin{tabular}{lcccc}
\hline Lithology & Thickness $(\mathrm{cm})$ & Material & $\begin{array}{c}\text { Ratio } \\
\text { Layers }\end{array}$ & $\begin{array}{c}\text { Strength } \\
(\mathrm{kPa})\end{array}$ \\
\hline Isolation layer & 1 & Paraffin : hydraulic oil : talcum powder : river sand: straw powder & $1: 2: 5.7: 34.2: 1$ & 2 \\
Soft rock layer & 3 & Sand: calcium carbonate : gypsum : water & $3.5: 3.5: 1.5: 1$ & 3 \\
Key strata & 2 & Sand: calcium carbonate : gypsum : water & $3: 3.5: 1.5: 1$ & 2 \\
Immediate roof & 3 & Sand: calcium carbonate : gypsum : water & $3.5: 3.5: 1.5: 1$ & 3 \\
\hline
\end{tabular}

the overlying strata, thus indicating that a stable balance is formed between the grouting and separation. The overpressure stage that usually occurs at the end stage of grouting indicates that the grouting speed is greater than the separation rate. The pressure stage provides a basis for experimental research on fluid flow.

2.2. Experimental System. To study the reproduce of grout flow in the overburden, we established a similar simulation system to emulate the overburden grouting process during underground mining with grouting. The system includes the main frame, grouting system, monitoring sensor, and acquisition software (Figure 3 ).

The main frame is made of a transparent Perspex sheet which can visualize the slurry flow. The inner dimensions of the frame are $1000 \times 300 \times 100 \mathrm{~mm}$ in length, width, and height. It is used to emulate coal seams, overlying strata, and the bedding separation fracture intended to be injected. At the bottom of the main frame is a movable thin slab with length, width, and thickness of 100,20 , and $1 \mathrm{~cm}$, respectively, which is used to emulate coal seam. The move of the thin slab emulates the coal-mining process and the formation of the gob area. A width of $5 \mathrm{~cm}$ is left between the two sides of the thin plate and the inner boundary of the frame to emulate the coal pillars on both sides of the longwall panel. Similar materials are laid above the thin slab in layers. These include the immediate roof, the main roof, the soft rock layer, and the isolation layer from bottom to top, with the thicknesses of 3,2,3, and $1 \mathrm{~cm}$, respectively (Figure 4).

The immediate roof, main roof, and soft rock layers are made of sand, calcium carbonate, gypsum, and water. These layers are used to emulate the caved and fractured zones above the gob area. The isolation layer is made of paraffin wax, hydraulic oil, talcum powder, river sand, straw powder, and water, with a solid-phase material ratio of $1: 2: 5.7: 34.2: 1$. The isolation layer directly below the separation fracture allows for nondisintegration, thus preventing the bleeding water from entering the lower rock layers and causing disintegration. The material ratio and characteristics of each rock layer are listed in Table 1. When laying each rock layer, mica was placed between layers to emulate the bedding. A space with a height of $0.5 \mathrm{~cm}$ was placed 




FIGURE 5: Locations of the sensors, borehole, and longwall panel (unit: $\mathrm{cm}$ ).

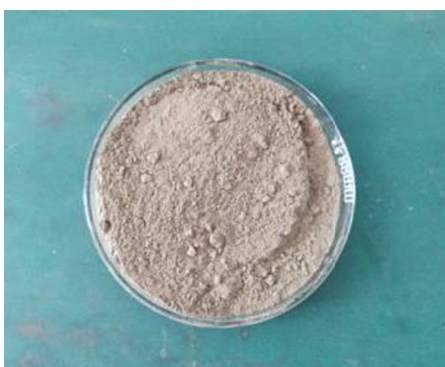

(a)



(b)

FIGURE 6: Injection material. (a) Fly ash and (b) injection slurry.

between the isolation layer and the upper cover plate of the main frame to emulate the initial separation zone that was intended to be injected.

The grouting system included a slurry mixer, a grouting pump, pipelines, and a borehole. The borehole is located at the top of the main frame. To monitor the slurry pressure at different positions in the separation fracture, four pressure sensors (\#1-4 in Figure 5) are evenly arranged on the center line of the upper cover plate of the main frame. Their distances to the holes are $20,40,60$, and $80 \mathrm{~cm}$ and are used to reflect the pressure difference at different positions. The thickness of the injection fill body was determined by monitoring the displacement of the lower isolation layer subject to the separation fracture. For this reason, three displacement sensors (S1-S3 in Figure 5) are arranged at equal intervals in the inclination direction of the main frame and are used to reflect the thickness differences in the boundary and the middle of the fracture. The relative positions of the pressure displacement sensor, borehole, and longwall working face are shown in Figure 5.

2.3. Experimental Methods. According to an engineering of isolated overburden grout injection, the fly ash slurry was selected as the injection material with a water-to-fly ash ratio of $1.6: 1$ (Figure 6). The grouting flow rate was determined to be $300 \mathrm{ml} / \mathrm{min}$. Before the extraction of the longwall face, grout was injected into the preset separation fracture until the injection pressure is formed, so as to simulate the flow of slurry in the nonpressure stage. Once the pressure develops, grouting during mining begins. The thin plate was extracted at a distance of $15 \mathrm{~cm}$ from the frame every $10 \mathrm{~min}$ to emulate the mining distance, and the coal seam was mined for six times. During this process, grouting in the bedding separation zone was performed simultaneously, and the slurry pressure and displacement of the isolation layer were monitored. To monitor the flow channel and consolidation of the slurry, a camera was used to capture pictures on the upper surface of the model for observation continually. In the grouting process, a colored tracer was added to the slurry to enhance the display of the results.

\section{Results and Discussion}

3.1. Slurry Flow. The slurry flow under the nonpressure and pressure stages are described based on the photographic monitoring results. During the nonpressure stage, the slurry flow manifested in two successive stages, namely, radial and bidirectional. During the radial flow stage, the slurry presented an approximate circular flow centered on the grouting hole, and the radius of the slurry diffusion increased as a function of the grouting time. When the front part of the slurry reached the boundary of the bedding separation zone, the slurry was transferred to the bidirectional flow because of the boundary constraint, that is, a planar flow along the left and right sides of the borehole (Figure 7). When the front 


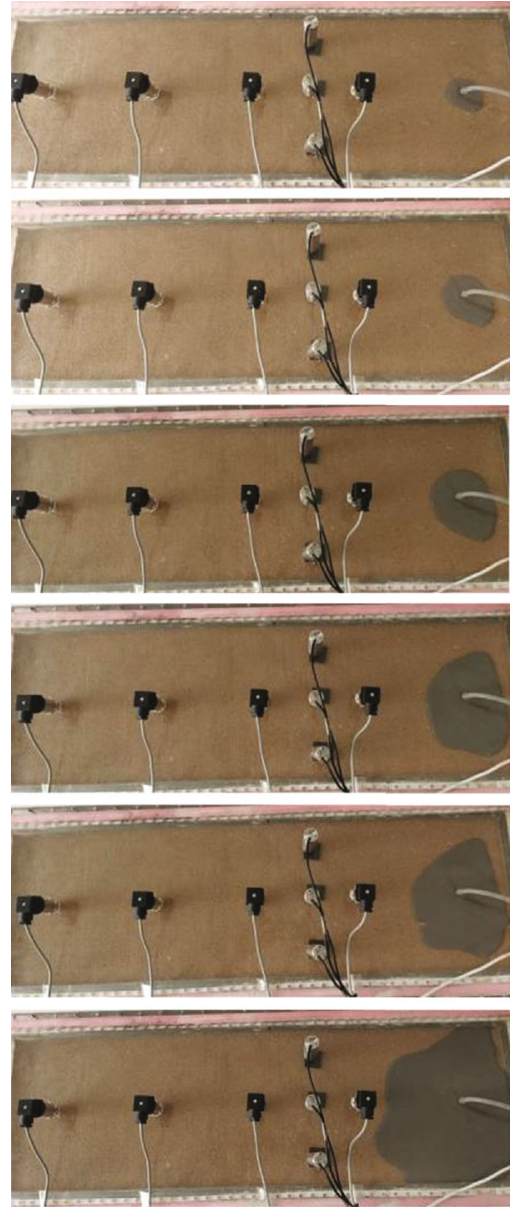

(a)
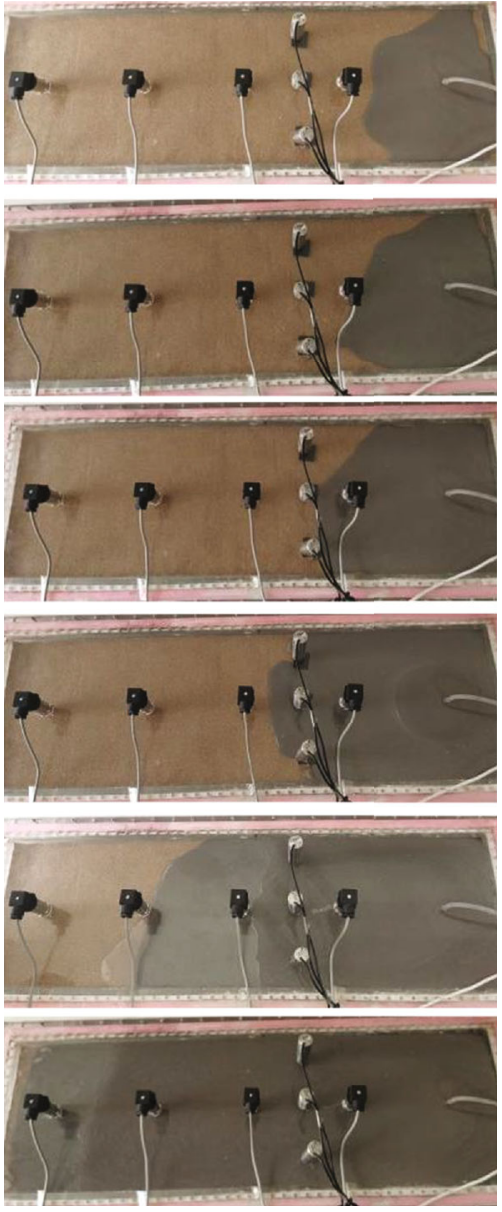

(b)

FIGURE 7: Slurry flow during nonpressure injection. (a) Radial flow (0-90 s). (b) Bidirectional flow (90-630 s).

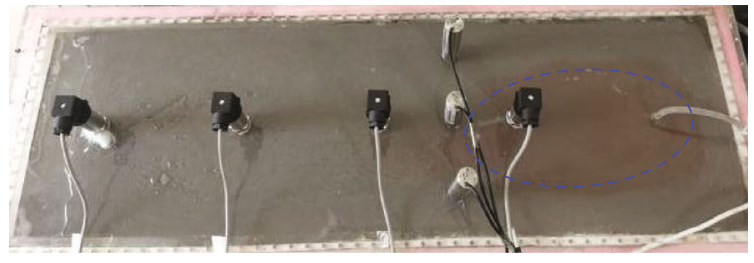

(a)



(b)



(c)

FIgURE 8: Slurry flow channel during pressurized injection. (a) $810 \mathrm{~s}$, (b) $1170 \mathrm{~s}$, and (c) $1770 \mathrm{~s}$.

of the slurry reached the right boundary, the slurry changed to one-sided flow owing to the boundary constraint.

Subject to the applied pressure, the slurry flow was no longer the plan flow, as in the case of nonpressure stage, but a dominant flow channel appeared. The channel was approximately elliptic with respect to the center of the grouting. As the grouting volume increased, the size of the channel expanded (Figure 8). The dominant flow channel expanded along the strike direction (i.e., face advance direction), and the channel width was smaller than its length before it 


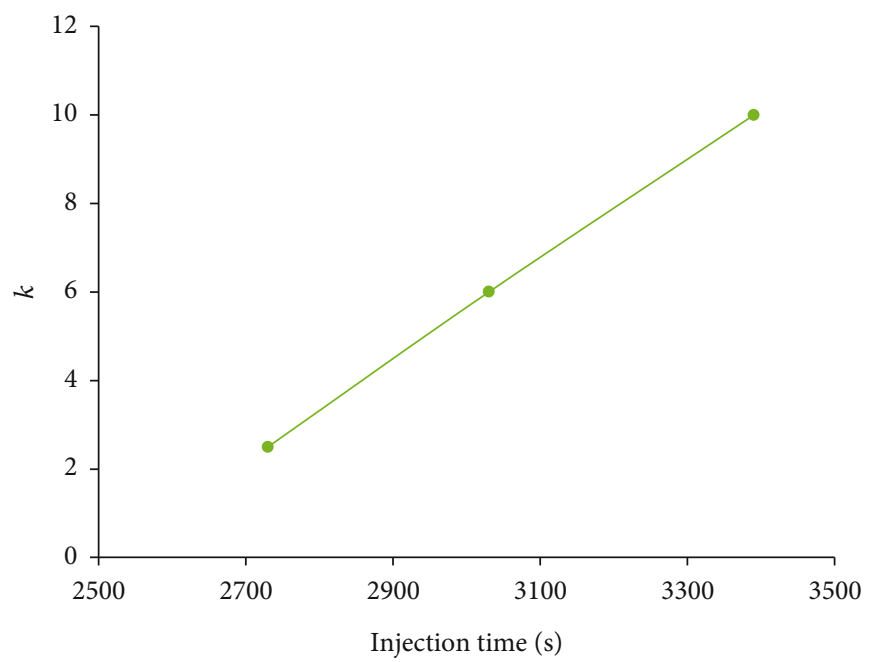

Figure 9: Flow channel coefficient $k$ vs. time.

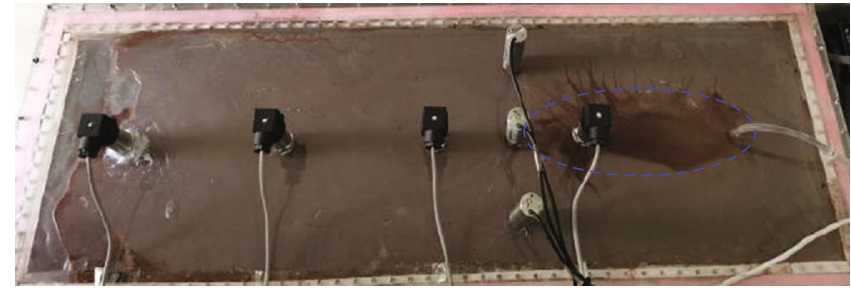

(a)

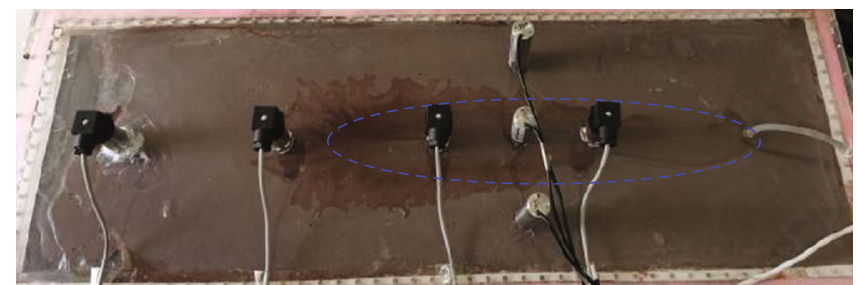

(b)

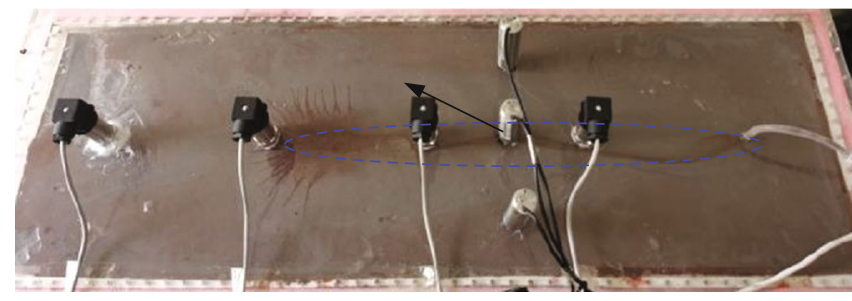

(c)

Figure 10: Evolution of slurry flow channel. (a) $2730 \mathrm{~s}$, (b) $3030 \mathrm{~s}$, and (c) $3390 \mathrm{~s}$.

reached the strike boundary of the separation zone. To characterize the dominant flow channel, we defined a flow channel coefficient $k$ as the ratio of the channel length to its width.

As the grouting volume and pressure continued to increase, the newly injected grout exerted the induced stress on the existing grout so that a shear channel was formed in the early-filled grout and allowed the new grout to flow along this channel. Meanwhile, the dominant flow channel was evolving: the value of $k$ continued to increase as the grouting time elapsed and is approximately linearly correlated with time (Figure 9). That is, the dominant flow channel gradually developed into a tabular shape (Figure 10). This is because the consolidation and deposition of the grout at the trend boundary occurred continually (refer to section 3.3).

3.2. Grouting Pressure Distribution. The grouting pressure distribution in the bedding separation fracture is an important factor that affects the slurry flow. It was found that the pressure at any point in the bedding separation increased as a function of the grouting time, and the pressure curves at different positions exhibited similar trends (Figure 11(a)). However, the pressure at different points in the separation was not equal. The grouting pressure decreased as a function of distance from the grouting hole, but the reduction was not large. In particular, the pressure differences for different positions gradually decreased as the injection time elapsed (Figure 11(b)). Setting of the grouting time at $1200 \mathrm{~s}$ (initial injection stage) generated the following pressures at sensors $\# 1-4$ of $82 \%, 43 \%, 36 \%$, and $7 \%$ of the hole pressure, respectively, while the pressure at \#4 (farthest from the borehole) was just $9 \%$ of that at \#1 (nearest to the borehole). If the grouting time was set at $3000 \mathrm{~s}$ (the end of grouting), the pressures at sensors \#1-4 reached 98\%, 93\%, 92\%, and 28\%, of the hole pressure, and the pressures at sensors \#1-3 were almost the same. The results showed that the grouting pressure decreased along the direction of slurry flow, but the differences were limited. It also indicated that the pressure at 


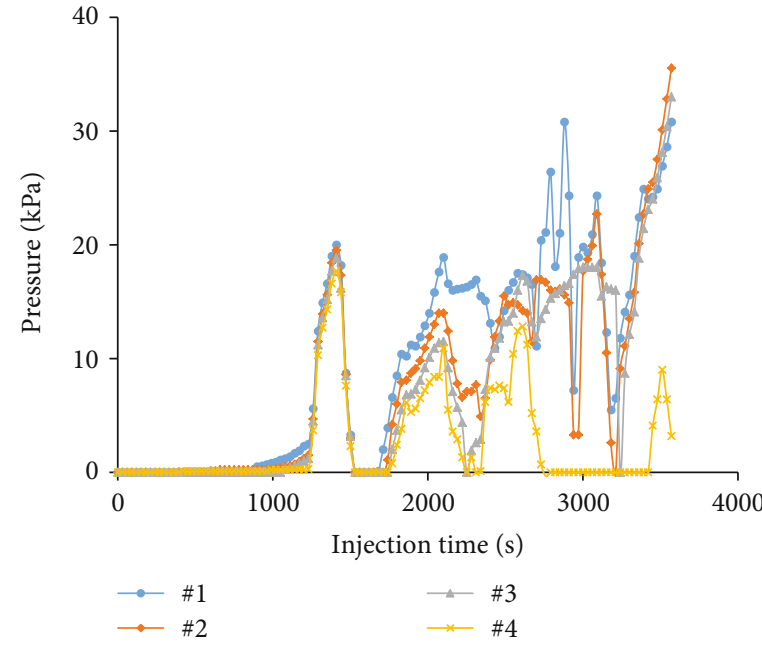

(a)



(b)

FIGURE 11: Slurry pressure as a function of (a) injection time and (b) distance.

any position can reflect the pressure trend in the entire bedding separation fracture.

3.3. Slurry Consolidation and Fill Distribution. To determine the consolidation characteristics of the slurry, it is necessary to determine the deposition rate of solid particles in the slurry. Water in the fly ash slurry serves as a carrier of solid particles. The flow velocity of the solid particles gradually decreases because of the bleeding of the slurry and final deposition. To prevent solid particles from depositing, the flow velocity should be greater than the critical nonsilting velocity [34]:

$$
v_{c}=0.2\left(1+3.4 C_{w}^{1 / 3} D^{1 / 4}\right) \beta,
$$

where $v_{c}$ is the critical nonsilting velocity, $C_{w}$ is the specific concentration of the solid mass, $D$ is the width of the flow channel, and $\beta$ is a coefficient that satisfies

$$
\beta=\left(r_{s}-1\right) / 1.7,
$$

where $r_{s}$ is the density of the ash particles. By substituting Equation (2) in Equation (1), we obtain

$$
v_{c}=0.12\left(1+3.4 C_{w}^{1 / 3} D^{1 / 4}\right)\left(r_{s}-1\right) .
$$

According to Equation (3), the critical nonsilting velocity of solid particles in fly ash slurry was determined to be $0.4 \mathrm{~m} / \mathrm{s}$.

The flow velocity of the slurry injected into the bedding separation fracture was constrained by the flow rate and the size of the separation fracture, and satisfied

$$
v=Q / w h,
$$

where $Q$ is the grouting flow, $w$ is the separation fracture width, and $h$ is the separation fracture height. According to
Equation (4), the velocity of the injected slurry at the bedding separation fracture was $0.0033 \mathrm{~m} / \mathrm{s}$, or just $0.8 \%$ of the critical nonsilting velocity. This indicates that the solid particle deposits (or the bleeding of slurry) occurred quickly following its entry from the borehole to the fracture. This was also verified in the experiment of the slurry flow.

The consolidation rate of the slurry at different positions of the bedding separation zone was not the same and was closely related to the slurry velocity. If the flow rate was low, the solid particles were expected to deposit fast; otherwise, the consolidation rate would be slower. Owing to the restriction of the boundary in the width direction, the flow velocity was smaller than that along the strike direction, and both were less than the critical nonsilting velocity. Therefore, the bleeding velocity in the width direction was greater than that in the strike direction. At distances closer to the boundary, the velocity was smaller. Therefore, the consolidation degree increased as the distance from the center increased along the width direction. The bleeding water gathered in the most anterior part of the slurry and formed a "water belt." The "water belt" moved to the boundary of the bedding separation zone subject to continuous pushing of the newly injected slurry. Finally, because of the action of the grouting pressure, the water in the "water belt" flowed to the underlying rock mass and was stored. Figure 12 shows the consolidation of the slurry in the separation fracture zone.

The fill thickness distribution in the width direction was determined with displacement sensors. In the initial stage of grouting (0-1200 s), there was no significant difference in the fill thickness, and the boundary fill thickness accounted for $84 \%$ of that in the center (Figure 13). As the gob volume increased, the amount of grouting also increased. Subject to the combined action of the mining effect and grouting pressure, the isolation layer began to exhibit deflection deformation that further allowed a large injectable space. At the end of mining (3000s), the fill thickness direction was different along the width direction. The thickness was approximately 


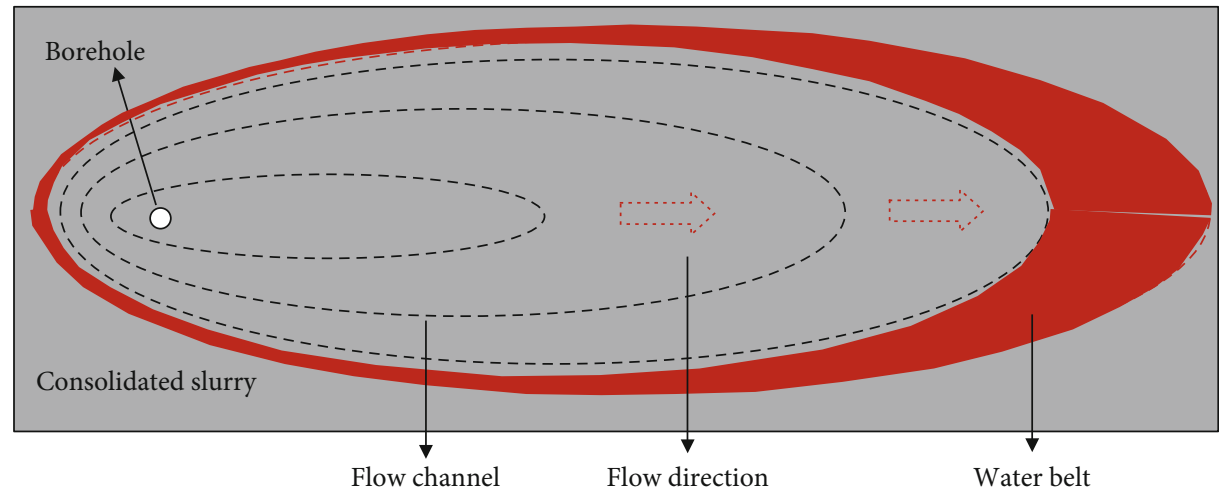

FIGURE 12: Schematic of slurry flow rule.



(a)

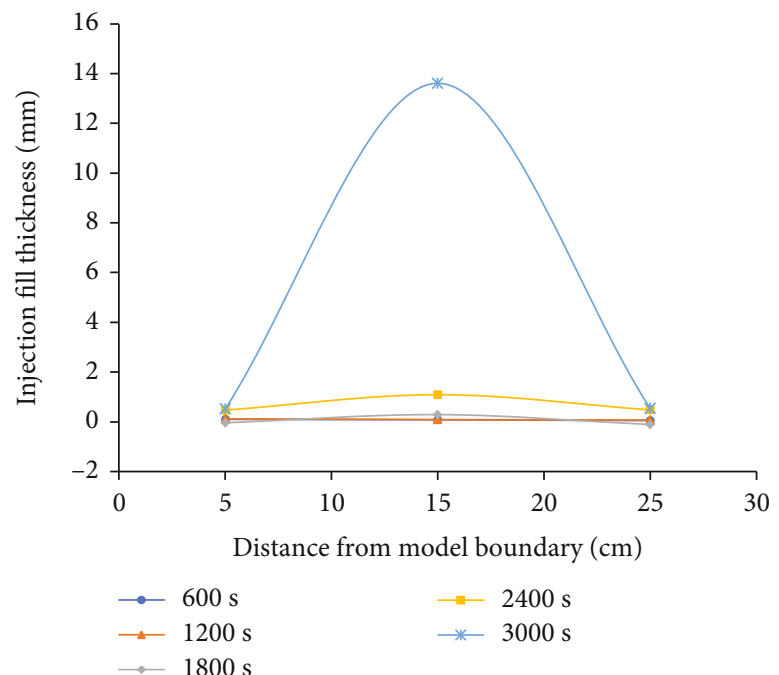

(b)

FIGURE 13: Distribution of injection fill. Fill thickness as a function of (a) time and (b) distance.

$0.53 \mathrm{~mm}$ on both sides (and accounted for $5.3 \%$ of the mining height), whereas that in the center reached $13.61 \mathrm{~mm}$, and accounted for $86.1 \%$ of the mining height. Thus, the thickness of the boundary fill was only $3.8 \%$ of that in the center, and the injection fill thickness distribution manifested as half pace, which is consistent with the model as described in [27]. This also indicates that the caved and fractured rocks are further compacted when subjected to the action of grouting pressure, thus allowing a larger injectable space above the isolation layer.

\section{Conclusions}

Mining-induced fractures formed in overburden by longwall mining are the key reasons for surface subsidence. Overburden grout injection technology uses these fractures to control mining subsidence. In this study, the flow of slurry in overburden fractures was studied experimentally.

The characteristics of slurry flow subject to nonpressure and pressure were obtained by photographic monitoring. In the nonpressure stage, slurry flows were manifested in the radial and bidirectional stages successively. In the pressure stage, the flow was presented as an almost elliptic dominant flow channel with its center on the grouting hole. This channel expanded gradually along the strike direction, and its size increased continually. The flow channel coefficient was proposed to represent the dominant channel at different pressure conditions. This increased in an efficient manner as the grouting time elapsed. This was attributed to the consolidation of the slurry at the boundary.

The distribution of the slurry pressure in the mining separation fracture was also revealed. The pressure at any point in the bedding separation increased as a function of grouting time. However, the pressure at different points in the separation was not equal. The grouting pressure decreased away from the grouting hole, but the reduction was not large. Nevertheless, it is interesting that the pressure curves at different positions exhibited similar trends. This provided the basis for the determination of borehole connectivity and pressure monitoring during longwall overburden grout injection.

The consolidation characteristics of the slurry were obtained. After entering the separation fracture, the flow 
velocity decreased significantly. This resulted in the deposition of solid particles and in the bleeding of the slurry. The slurry consolidation rate was not the same at each position, and it was greater in the width direction than that in the strike direction. In particular, the closer the slurry was to the boundary, the smaller the velocity. That is, the farther from the borehole, the greater the degree of slurry consolidation. The bleeding water gathered at the anterior part of the slurry and formed a "water belt," which moved to the boundary of the bedding fracture. Finally, the water in the "water belt" flowed toward the underlying rock mass and was stored because of the action of the grouting pressure. The fill thickness increased as a function of the grouting and mining times. This indicated that the caved and fractured rock mass was further compacted that allowed a large injectable space above the isolation layer. This finding may improve the estimation of the injection ratio.

\section{Data Availability}

The research data used to support the findings of this study may be released upon request addressed to the corresponding author who can be contacted at Li_Jian@cumt.edu.cn. Some or all data, models, or code generated or used during the study are available from the corresponding author upon request (experimental equipment parameters, laboratory experimental results data, field experimental results, etc.).

\section{Conflicts of Interest}

The authors declare that there are no conflicts of interest regarding the publication of this paper.

\section{Acknowledgments}

This work was supported by the National Natural Science Foundation of China (51604258) and the China Scholarship Council (201906425004).

\section{References}

[1] V. Palchik, "Formation of fractured zones in overburden due to longwall mining," Environmental Geology, vol. 44, no. 1, pp. 28-38, 2003.

[2] C. Ö. Karacan and R. A. Olea, "Inference of strata separation and gas emission paths in longwall overburden using continuous wavelet transform of well logs and geostatistical simulation," Journal of Applied Geophysics, vol. 105, pp. 147-158, 2014.

[3] V. Palchik, "Localization of mining-induced horizontal fractures along rock layer interfaces in overburden: field measurements and prediction," Environmental Geology, vol. 48, no. 1, pp. 68-80, 2005.

[4] V. Palchik, "Experimental investigation of apertures of mining-induced horizontal fractures," International Journal of Rock Mechanics and Mining Sciences, vol. 47, no. 3, pp. 502-508, 2010.

[5] D. P. Adhikary and H. Guo, "Modelling of longwall mininginduced strata permeability change," Rock Mechanics and Rock Engineering, vol. 48, no. 1, pp. 345-359, 2015.
[6] Y. Li, C. Wu, and B. A. Jang, "Effect of bedding plane on the permeability evolution of typical sedimentary rocks under triaxial compression," Rock Mechanics and Rock Engineering, 2020.

[7] S. G. Chen and W. Hu, "A comprehensive study on subsidence control using COSFLOW," Geotechnical Geological Engineering, vol. 27, no. 3, pp. 305-314, 2009.

[8] D. Xuan, J. Xu, B. Wang, and H. Teng, "Borehole investigation of the effectiveness of grout injection technology on coal mine subsidence control," Rock Mechanics and Rock Engineering, vol. 48, no. 6, pp. 2435-2445, 2015.

[9] G. Wang, Y. Guo, C.'a. du et al., "Experimental study on damage and gas migration characteristics of gas-bearing coal with different pore structures under sorption-sudden unloading of methane," Geofluids, vol. 2019, Article ID 7287438, 11 pages, 2019.

[10] X. Peng, S. Zhu, Z. You et al., "Numerical simulation study of fines migration impacts on an early water drainage period in undersaturated coal seam gas reservoirs," Geofluids, vol. 2019, Article ID 5723694, 16 pages, 2019.

[11] F. Wang, W. Wang, B. Wu, Q. Bai, and M. S. A. Perera, "Mechanism, cause, and control of water, solutes, and gas migration triggered by mining activities," Geofluids, vol. 2019, Article ID 5789152, 4 pages, 2019.

[12] H. Guo, D. P. Adhikary, and M. S. Craig, "Simulation of mine water inflow and gas emission during longwall mining," Rock Mechanics and Rock Engineering, vol. 42, no. 1, pp. 25-51, 2009.

[13] G. Hu, W. He, and C. Lan, "Sealing behavior and flow mechanism of expandable material slurry with high water content for sealing gas drainage boreholes," Geofluids, vol. 2018, Article ID 2954306, 15 pages, 2018.

[14] Q. Qu, J. Xu, R. Wu, W. Qin, and G. Hu, “Three-zone characterisation of coupled strata and gas behaviour in multi-seam mining," International Journal of Rock Mechanics and Mining Sciences, vol. 78, pp. 91-98, 2015.

[15] S. G. Chen and H. Guo, "Numerical simulation of bed separation development and grout injecting into separations," Geotechnical and Geological Engineering, vol. 26, no. 4, pp. 375-385, 2008.

[16] B. Shen and B. Poulsen, "Investigation of overburden behaviour for grout injection to control mine subsidence," International Journal of Mining Science and Technology, vol. 24, no. 3, pp. 317-323, 2014.

[17] D. Xuan and J. Xu, "Longwall surface subsidence control by technology of isolated overburden grout injection," International Journal of Mining Science and Technology, vol. 27, no. 5, pp. 813-818, 2017.

[18] J. Xu, J. Ni, D. Xuan, and X. Wang, "Coal mining technology without village relocation by isolated grout injection into overburden," Coal Science and Technology, vol. 43, pp. 8-11, 2015.

[19] H. Teng, J. Xu, D. Xuan, and B. Wang, "Surface subsidence characteristics of grout injection into overburden: case study of Yuandian No. 2 coalmine, China," Environmental Earth Sciences, vol. 75, no. 6, p. 530, 2016.

[20] B. Wang, J. Xu, and D. Xuan, "Time function model of dynamic surface subsidence assessment of grout-injected overburden of a coal mine," International Journal of Rock Mechanics and Mining Sciences, vol. 104, pp. 1-8, 2018.

[21] D. Xuan and J. Xu, "Grout injection into bed separation to control surface subsidence during longwall mining under 
villages: case study of Liudian coal mine, China," Natural Hazards, vol. 73, no. 2, pp. 883-906, 2014.

[22] D. Xuan, J. Xu, and W. Zhu, "Dynamic disaster control under a massive igneous sill by grouting from surface boreholes," International Journal of Rock Mechanics and Mining Sciences, vol. 71, pp. 176-187, 2014.

[23] H. Guo, B. Shen, and S. Chen, "Investigation of overburden movement and a grout injection trial for mine subsidence control," in Rock Mechanics: Meeting Society's Challenges and Demands, pp. 1559-1566, American Rock Mechanics Association, 2007.

[24] Y. Chen, T. Nishiyama, M. Terada, and Y. Iwamoto, "A fluorescent approach to the identification of grout injected into fissures and pore spaces," Engineering Geology, vol. 56, no. 3-4, pp. 395-401, 2000.

[25] H. Alehossein, "Viscous, cohesive, non-Newtonian, depositing, radial slurry flow," International Journal of Mineral Processing, vol. 93, no. 1, pp. 11-19, 2009.

[26] H. Alehossein, B. Shen, Z. Qin, and C. Huddlestone-Holmes, "Flow analysis, transportation, and deposition of frictional viscoplastic slurries and pastes in civil and mining engineering," Journal of Materials in Civil Engineering, vol. 24, no. 6, pp. 644-657, 2012.

[27] D. Xuan, J. Xu, B. Wang, and H. Teng, "Investigation of fill distribution in post-injected longwall overburden with implications for grout take estimation," Engineering Geology, vol. 206, pp. 71-82, 2016.

[28] M. J. Yang, Z. Q. Yue, P. K. K. Lee, B. Su, and L. G. Tham, "Prediction of grout penetration in fractured rocks by numerical simulation," Canadian Geotechnical Journal, vol. 39, no. 6, pp. 1384-1394, 2002.

[29] S. C. Li, Z. Zheng, R. T. Liu, X. C. Wang, L. Z. Zhang, and H. B. Wang, "Analysis of the grouting diffusion mechanism of micro-fractures considering the coupling effect of grouting and rock," Chinese Journal of Rock Mechanics and Engineering, vol. 36, pp. 812-820, 2017.

[30] X. C. Wang, R. T. Liu, W. M. Yang et al. , "Study on grouting mechanism of horizontal fractures considering the bleeding of cement slurry," Chinese Journal of Rock Mechanics and Engineering, vol. 38, pp. 1005-1017, 2019.

[31] J. Xu, D. Xuan, W. Zhu, and X. Wang, "Partial backfilling coal mining technology based on key strata control," Journal of Mining and Strata Control Engineering, vol. 1, pp. 135041135048, 2019.

[32] L. Zhang, J. Xu, D. Xuan, and M. Gan, "Experimental and applied research on compression properties of slurry used for isolated overburden grout injection," Journal of China Coal Society, vol. 42, pp. 1118-1123, 2017.

[33] H. Teng, Formation Mechanism of Compacting Area in the Gob with Grouting Into Overburden of Isolated Panels during Longwall Mining, China University of Mining and Technology, Xuzhou, China, 2017.

[34] C. Wang, J. Xu, and D. Xuan, "Blockage mechanism of ground transport pipeline for isolated overburden grout injection," Journal of China Coal Society, vol. 43, pp. 2703-2708, 2018. 